\section{Evaluation model of plate waste to monitor food consumption in two different catering settings}

\author{
Stefano Saccares, ${ }^{1}$ \\ Umberto Scognamiglio, ${ }^{2}$ Catia Moroni, ${ }^{3}$ \\ Alessandra Marani, ${ }^{4}$ \\ Veronica Calcaterra, ${ }^{4}$ \\ Mariano Amendola, ${ }^{4}$ Giulia Civitelli, ${ }^{4}$ \\ Maria Sofia Cattaruzza, ${ }^{4}$ \\ Arianna Ermenegildi, ${ }^{1}$ Valeria Morena ${ }^{1}$ \\ ${ }^{1}$ Centro Studi per la Sicurezza \\ Alimentare, Istituto Zooprofilattico \\ Sperimentale delle Regioni Lazio e \\ Toscana, Roma; ${ }^{2}$ Nutritional Consultant, \\ Ariccia (RM); ${ }^{3}$ Dipartimento di Sanità \\ Pubblica e Malattie Infettive, Università \\ di Roma La Sapienza; ${ }^{4}$ Facoltà di \\ Medicina e Psicologia, Università di Roma \\ La Sapienza, Italy
}

\section{Abstract}

An increasing number of people regularly eats lunch away from home, using catering services. In this context, therefore, it is extremely important to improve the meals' quality, remaining faithful to the principles of hygiene, nutritional and organoleptic quality and proper food handling. At the same time, it is necessary to promote food choices, nutritionally correct, by evaluations of appropriateness of menus. The study of food waste allows an evaluation of the nutritional habits of consumers and an important economic consideration of the costs incurred for the implementation of the service. This becomes even more important in some particularly sensitive groups, such as children and elderly. The purpose of this work is to test a model of semiquantitative evaluation of waste to monitor food consumption in two different catering contexts (educational and business), in order to improve the service for school students and other consumers.

\section{Introduction}

The recent changes in lifestyle in our society have resulted in an increase in the number of people who eat at least one meal outside their home, using more the public catering: school, hospital and commercial catering (Guidarelli, 2008; Iapello et al., 2011; Monasta et al., 2010). A very important aspect about the risk of an inadequate diet concerns the limited knowledge on food consumption. This is still a little studied question and needs further researches.

As well as a food excess can result in a high increse of body weight, an insufficient feeding can cause serious nutritional deficiencies (Saccares et al., 2012). Therefore, knowing quantitatively and qualitatively what we eat is an important goal for those who work in the offer and promotion of advice to improve our nutritional status. So, performing a waste assessment can provide useful information (Buzby and Guthrie, 2002; Carr and Levins, 2000).

The purpose of our work was just to test one of the possible tools in the assessment of food consumption. In particular, we wanted to measure the amount and composition of food waste to monitor the satisfaction and the nutritional aspect, in order to carry out any action to improve the service for both, the students and the hospital staff, but also for the rest of the population. After identifying the best methodology, it will be possible to validate the model for evaluating of food waste in different catering settings to improve the service and make a self-assessment in terms of hygiene and nutrition.

\section{Materials and Methods}

This work is based on two surveys for the semiquantitative evaluation of food waste. The first was conducted in 2011 in ten school cafeterias in Rome, of which five of primary school and five of kindergarten, with the same menu. The data were collected for two weeks, from 36 primary school classes and 11 kindergarten classes, involving a total of 4775 meals.

One week was on winter menu and the other on the summer menu. The meals were prepared by one cooking centre, located in a school involved in testing and distributed in other institutes. The second observation was made in 2012 at the cafeteria of St. Andrea Hospital in Rome. The data were collected for nine days, on the summer menu, monitoring about 2000 meals. The evaluation of food waste was carried out, in both cases, using a questionnaire for the semiquantitative evaluation of food waste, similar to that successful tested in previous studies (Saccares et al., 2012; Scognamiglio et al., 2012). In the school survey, data were collected from ten teachers (one for school), in cafeteria of St. Andrea Hospital the questionnaire was self-administered from consumers (students, internal staff, external consumers) and returned, at the end of the meal, to collection staff. The aim was to further confirm the sustainability of the protocol designed for school cafeterias and test the applicability in different settings of catering.
Correspondence: Stefano Saccares, Centro Studi per la Sicurezza Alimentare, Istituto Zooprofilattico Sperimentale delle Regioni Lazio e Toscana, via Appia Nuova 1411, 00178 Roma, Italy.

Tel./Fax: +39.06.79099312

E-mail: stefano.saccares@izslt.it

Key words: School catering, Hospital catering, Plate waste, Healthy diet, Food consumption.

Conflict of interests: the authors declare no potential conflict of interests.

Contributions: CM, AM, VC, MA, GC, MSC, data collection at St. Andrea Hospital cafeteria; SS, AE, $\mathrm{VM}$, management of data collection in school cafeterias of Ariccia, comparison with data from St. Andrea Hospital cafeteria, processing and writing of conclusions; US, processing of questionnaire for the semiquantitative evaluation of food waste, collaboration in processing and writing of conclusions.

Received for publication: 10 May 2013

Revision received: 4 November 2013

Accepted for publication: 16 November 2013.

This work is licensed under a Creative Commons Attribution 3.0 License (by-nc 3.0).

(C) Copyright S. Saccares et al., 2014

Licensee PAGEPress, Italy

Italian Journal of Food Safety 2014; 3:1669

doi:10.4081/ijfs.2014.1669

The questionnaire consisted of three parts: the first contained general information (class, section, date of the survey), the second concerned the percentages of waste relative for each dish $(0-25,50,75,100 \%)$ and finally, the third section included information about the daily menu and any comments. The questionnaire was partially modified for hospital survey to adapt to the differences in the users and the service offered. In particular, the model included a first section for personal data, a second to fill with the menu chosen and the last with the percentage of waste for each dish. The fourpoint scale used for detection of waste remained unchanged. Then, for the evaluation of the liking of each dish the percentage of dishes with the less waste (25-0\%) was analysed, and, among these, dishes less appreciated were identified.

In both cases, before the beginning of the evaluation, the questionnaire had been described to the observers specifying the method of compilation. About school cafeterias, a meeting attended by an officer of the catering company, the teaching staff and the experts of the Study Centre for Food Safety (Centro di Studi per la Sicurezza Alimentare, CSA) was organised. Also, a graduating student of CSA who helped teachers in colleting 
data and used them for his thesis was present. In cafeteria of St. Andrea Hospital, users of the cafeteria had been informed in advance of the survey through the placement of specific posters. In addition, each questionnaire contained the istructions for completion.

\section{Results}

Data collected in school cafeterias showed the following. The side dish were the least appreciated meals, while the second courses and majority of first courses had a sufficient appreciation, although the quantities consumed by each child were often lower than those suggested by levels of recommended daily intake of nutrients for the Italian population (SINU, 2006) (Figure 1). In kindergartens, the plate waste of various dishes was lower than those detected in primary schools. Simple dishes were most accepted: for example macaroni with meat sauce were totally consumed from $84.2 \%$ of children, $70.0 \%$ of pupils liked macaroni with tomato sauce, $68.4 \%$ liked potato omelette, $60.9 \%$ ate ham and melon, $46.3 \%$ consumed lettuce and $44.7 \%$ of pupils liked spinach with olive oil. With particolar reference to winter menu, some meals served in the school - where the cooking centre is were discarded less than in other complexes where the same meals are delivered to $(2 \%$ of waste compared to $18 \%$ for rice balls, $7 \%$ compared to $41 \%$ for macaroni with beans; $7 \%$ compared to $29 \%$ for veal). Data are corroborated by the opinion expressed by the teachers on the food temperature: this is adequate in the school where the cooking centre is, but it is not always the same in the others institute where meals are delivered to.

The data resulting from the St. Andrea Hospital cafeteria in Rome showed wastes lower than school cafeterias especially for waste between 75 and 100\% (Tables 1 and 2; Figure 2). The higher frequencies were found for lower waste, between 0 and 25\% (Table 2). Assuming this range as an indicator of the liking, it was possible to identify both less con- sumed and most accepted dishes. Among the less consumed dishes there are macaroni with shrimp and zucchini as first course, roast beef with tartar souce as second course, ricotta cheese as special dish and cauliflower as side dish. The most accepted dishes, instead, were:

Table 1. Waste for each course in school cafeterias expressed in frequency and percentages.

\begin{tabular}{|c|c|c|c|c|c|c|}
\hline & \multicolumn{4}{|c|}{ Waste (\%) } & \multirow{2}{*}{$\begin{array}{l}\text { Missing } \\
\text { data (\%) }\end{array}$} & \multirow[t]{2}{*}{ Tota } \\
\hline & A & B & C & D & & \\
\hline First course & $\begin{array}{c}1071 \\
(24.6)\end{array}$ & $\begin{array}{c}373 \\
(8.6)\end{array}$ & $\begin{array}{c}748 \\
(17.2)\end{array}$ & $\begin{array}{c}2165 \\
(49.7)\end{array}$ & $\begin{array}{l}418 \\
(9.6)\end{array}$ & 4357 \\
\hline Second course & $\begin{array}{c}1278 \\
(29.2)\end{array}$ & $\begin{array}{c}343 \\
(7.8)\end{array}$ & $\begin{array}{c}722 \\
(16.5)\end{array}$ & $\begin{array}{c}2033 \\
(46.5)\end{array}$ & $\begin{array}{c}399 \\
(9.1)\end{array}$ & 4376 \\
\hline Side dish & $\begin{array}{l}2231 \\
(51.0)\end{array}$ & $\begin{array}{c}322 \\
(7.3)\end{array}$ & $\begin{array}{c}485 \\
(11.1)\end{array}$ & $\begin{array}{c}1339 \\
(30.6)\end{array}$ & $\begin{array}{c}398 \\
(9.1)\end{array}$ & 4377 \\
\hline Fruit & $\begin{array}{c}1346 \\
(37.2)\end{array}$ & $\begin{array}{c}173 \\
(4.8)\end{array}$ & $\begin{array}{c}381 \\
(10.5)\end{array}$ & $\begin{array}{c}1723 \\
(47.6)\end{array}$ & $\begin{array}{c}1152 \\
(31.8)\end{array}$ & 3623 \\
\hline Bread & $\begin{array}{l}1361 \\
(38.9)\end{array}$ & $\begin{array}{l}260 \\
(7.4)\end{array}$ & $\begin{array}{c}444 \\
(12.7)\end{array}$ & $\begin{array}{r}1438 \\
(41.1)\end{array}$ & $\begin{array}{c}1272 \\
(36.3)\end{array}$ & 3503 \\
\hline
\end{tabular}

A, $100 \%$ waste; B, $75 \%$ waste; C, $50 \%$ waste; D, $25-0 \%$ waste.

Table 2. Waste for each course in St. Andrea Hospital cafeteria expressed in frequency and percentages.

\begin{tabular}{|c|c|c|c|c|c|c|}
\hline & \multicolumn{4}{|c|}{ Waste (\%) } & \multirow{2}{*}{$\begin{array}{l}\text { Missing } \\
\text { data (\%) }\end{array}$} & \multirow[t]{2}{*}{ Total } \\
\hline & A & B & C & D & & \\
\hline First course & $\begin{array}{c}76 \\
(4.7)\end{array}$ & $\begin{array}{c}70 \\
(4.3)\end{array}$ & $\begin{array}{c}112 \\
(6.9)\end{array}$ & $\begin{array}{c}943 \\
(58.2)\end{array}$ & $\begin{array}{c}448 \\
(27.7)\end{array}$ & 1619 \\
\hline Second course & $\begin{array}{c}45 \\
(2.7)\end{array}$ & $\begin{array}{c}39 \\
(2.4)\end{array}$ & $\begin{array}{c}110 \\
(6.7)\end{array}$ & $\begin{array}{c}735 \\
(45.2)\end{array}$ & $\begin{array}{c}697 \\
(42.8)\end{array}$ & 1626 \\
\hline Side dish & $\begin{array}{c}60 \\
(3.6)\end{array}$ & $\begin{array}{c}90 \\
(5.4)\end{array}$ & $\begin{array}{c}152 \\
(9.1)\end{array}$ & $\begin{array}{c}906 \\
(54.6)\end{array}$ & $\begin{array}{c}450 \\
(27.1)\end{array}$ & 1658 \\
\hline Fruit & $\begin{array}{c}72 \\
(4.4)\end{array}$ & $\begin{array}{c}31 \\
(1.9)\end{array}$ & $\begin{array}{c}31 \\
(1.9)\end{array}$ & $\begin{array}{c}912 \\
(55.7)\end{array}$ & $\begin{array}{c}591 \\
(36.1)\end{array}$ & 1637 \\
\hline Special dish & $\begin{array}{c}21 \\
(1.9) \\
\end{array}$ & $\begin{array}{c}12 \\
(0.7)\end{array}$ & $\begin{array}{c}54 \\
(3.3) \\
\end{array}$ & $\begin{array}{c}344 \\
(21.1)\end{array}$ & $\begin{array}{r}1193 \\
(73.4) \\
\end{array}$ & 1624 \\
\hline
\end{tabular}

A, $100 \%$ waste; B, $75 \%$ waste; C, 50\%waste; D, 25-0\% waste.

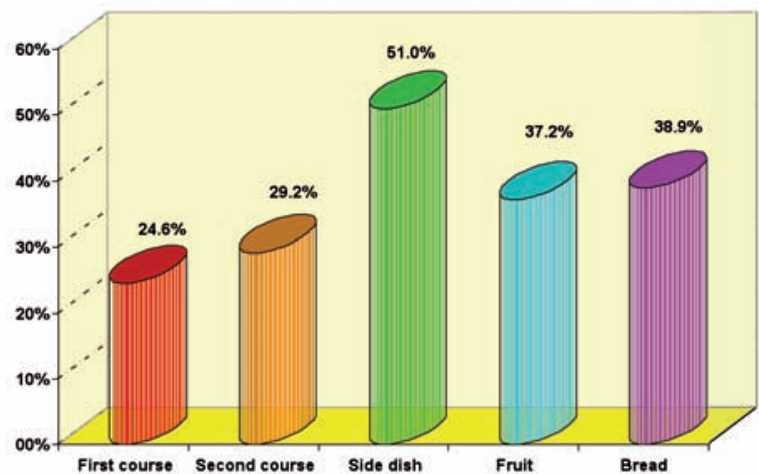

Figure 1. Percentage of dishes totally rejected in school cafeterias.

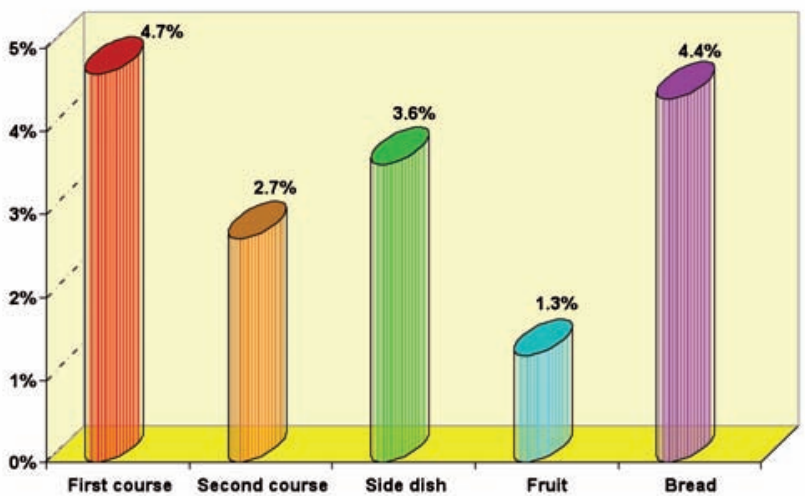

Figure 2. Percentage of dishes totally rejected in St. Andrea Hospital cafeteria. 
macaroni with salmon, chicken salad, robiola cheese and grilled vegetables.

In both cases, some information has been omitted by teachers or the consumers who completed the questionnaire, but a treatment for missing data was not carried out.

\section{Discussion}

The existence of guidelines for the preparation of balanced meals according to the nutritional aspect is often not enough to ensure adequate intake of nutrients for those who use the catering service. This depends on the food waste that is daily present in cafeterias. Although in some situations waste is very limited, one of the critical points of public catering, in particular in school cafeterias, is the large amount of food waste produced (Buzby and Guthrie, 2002; Carr and Levins, 2000; Iapello et al., 2011; La Pira, 2012a, 2012b; Saccares et al., 2012). The main consequence is the possibility that there may be situations of nutritional imbalances.

The causes are numerous and different and this explains why a certain amount of waste is unavoidable, but an excessive waste can be a symptom of inefficient operations and/or inadeguate distribution system. Performing a waste assessment, therefore, can yield useful information and be of great benefit. The literature shows that studies on food waste were used to calculate costs, evaluate the popularity of food and the nutritional intake, obtain information about the operations of preparation and distribution of meals (Buzby and Guthrie, 2002; Carr and Levins, 2000; Iapello et al., 2011). Waste can be assessed with different methodologies. The most common methods used are physical measurement of plate waste (such as weighing discarded food), food consumption as recalled by consumers and visual estimates. The physical method involves the double weighing of food. A randomly selected set of lunch trays are taken from the serving line and the edible food items are weighed. Later, after the users have finished eating, the leftovers of each edible food item are weighed. The primary advantage of this method is that it can provide detailed and accurate plate waste information. Disadvantages are the cost, the time necessary for the execution, the availability of space for storing food until the time of weighing. It also requires a careful training of personnel and it is not feasible for a number of samples high (max. 100). The second method is based on the memory of the subjects. These are instructed to fill out a questionnaire in which they have to indicate the amount of food consumed and waste. It can be combined with a personal interview. It is less expensive, less time consuming, and cleaner than direct phys- ical weighing, but it has the great disadvantage of being limited by the memory of individuals. This self-estimation is subject to bias. Finally the visual method is based on the observation and evaluation of food left on the plates by trained observers. Observers report the information on a questionnaire that has a rating scale waste. The most used are fivepoints scales, but there are also scales with less or more points. Advantages of the method are the simplicity of implementation, low cost and speed. Also the number of observers is limited. Scales with more points provide more precise information but they need more attention. The main disadvantage is that the portions are not made on exact proportions (Buzby and Guthrie, 2002; Carr and Levins, 2000).

In our study we used the visual method for its advantages and because its accuracy had been already assessed in previous studies (Saccares et al., 2012; Scognamiglio et al., 2012). Through the application of this method it was possible to obtain hygienic, sanitary, sensory, economic and nutritional information, thus offering to the responsible for the management of the cafeterias the opportunity to monitor the quality and satisfaction of the service. Hygienic information derives from a direct assessment of the consumer (presence of physical contaminants in the food, presence of mold, etc.); sanitary information, instead, is indirect because, in the case of food-borne, it is possible to identify all users that consumed the contaminated food.

The data obtained in the two investigations, in the school and in the hospital cafeterias, are not exactly comparable, for some reasons: the study population had various ages and therefore also a different knowledge about a healthy diet; in addition, the menu in school cafeterias was fixed, in the hospital the users had the possibility to choose the menu based on their personal preferences. However, in both cases, the questionnaire adopted provided the desired information. In fact, in the case of children it was possible to assess the actual caloric and nutritional intake during the main meal. We observed also that in kindergartens the plate waste of various dishes was lower than those detected in primary schools. In our opinion, this difference is probably due to the extra time that kindergartens teachers devote at meal time and to the lower resistance of children to taste food. This is a significant fact because an excessive waste during the lunch can be a potential danger for the health of children and certainly represents a significant economic loss (Buzby and Guthrie, 2002; Iapello et al., 2011; La Pira, 2012a, 2012b). In fact, the economic value of food waste in the school cafeterias during the sperimentation was approximately EUR 8000. It is about 53.0\% of a total of 15,000 euro. In addition there is the cost for the waste disposal. Even in the hospital cafeteria it was possible to evaluate the acceptability of each course according to the discards observed. The data will be shared with the customers of the catering service and presented to the users of the cafeteria, in order to reduce waste and improve the quality of service offered. About missing data, probably they may have partially affected the final result, but in this preliminary study our priority was to test the method. Further experiments are required to refine the method and statistical analysis.

\section{Conclusions}

The primary goal of a good policy of catering is the convergence of economic logic with the priority of health. In this sense, an evolved system of catering must have more purposes, in particular to achieve and maintain a high level of quality of the meals as nutritional and sensory quality, producing and distributing meals in accordance with the indications of the levels of recommended daily intake of nutrients for the Italian population (SINU, 2006), remaining faithful to the principles of food safety. The public catering should not be regarded only as a satisfaction of nutrient needs but as a moment of education and health promotion promoting the adoption of healthy eating habits for the prevention of diseases which malnutrition is one of the main risk factors. Malnutrition may be due to a nutritional excess or to a deficiency. Unfortunately this second aspect is often understimated. Therefore, knowing quantitatively and qualitatively what we eat is an important goal. Among the different methodologies for the evaluation of food consumption of particular interest is the one that evaluates the amount of food waste. In particular, the application of this visual method gave much information that offers different opportunities: i) to change the menus proposed by replacing the plates consumed less with others most accepted, respecting the indications of nutritionists; ii) to estimate the cost of the leftover and to search for the causes in order to reduce the waste; iii) to monitor pupils of different age in order to plan educational interventions to families; iv) to monitor individual pupils in order to initiate intervention programs for each subject by working in synergy with the activities of the pediatrician; v) to assess the total quality of the catering service through the assessment of different parameters (temperature, cooking, variety and presentation of the meals, presence of contaminats, etc.) for the purpose to schedule corrective actions; vi) to have objective information on the consumption of the meal in case of a food-borne disease. Finally, the study allowed us to test the proposed 
model. The instrument should be refined and validated through further experiments but at the same time the study confirmed its strengths: the simplicity of the proposed model that can be used by trained people but not necessarily highly qualified and the cheapness and the rapidity of the method compared to others.

The ability and experience of the observers are the most important conditions to obtain reliable data because a visual estimation by an expert evaluator can be made by department/classroom/dining hall and it can provide data most representative of reality.

\section{References}

Buzby JC, Guthrie JF, 2002. Plate waste in food school nutrition programs. Final report to congress. Available from: http://www.ers.usda.gov/media/887982/efa n02009.pdf

Carr D, Levins J, 2000. Plate waste studies. Pratical Reserch 3-1/3-17. National Food Service Management Institute, University of Mississippi Publ., Jackson, MS, USA.
Guidarelli L, 2008. [La ristorazione collettiva. Interventi e proposte]. [Article in Italian]. Available from: http://www.ccmnetwork.it/documenti_Ccm/convegni/SANI T/materiali2008/25.6/6-Ristorazione_collettiva_Guidarelli.pdf

Iapello A, Quaglia GB, Di Renzo L, De Lorenzo A, Bucarelli FM, 2011. [Indagine qualiquantitativa dello scarto alimentare nella refezione scolastica, con particolare riferimento agli aspetti nutrizionali]. [Article in Italian]. Available from: http://www.ilfattoalimentare.it/wp-content/uploads/2013/03/iapello-et-al-la-rivista-di-scienza-dellalimentazione-2011.pdf

La Pira R, 2012a. [Mense scolastiche basta con gli sprechi, metà del cibo finisce nei rifiuti. Il caso di Milano Ristorazione]. [Article in Italian]. Available from: http://www.ilfattoalimentare.it/mense-scolastiche-milano-ristorazione-spreco.html

La Pira R, 2012b. [Sprechi alimentari, nelle scuole milanesi il $40 \%$ del pasto dei bambini finisce nella spazzatura. Basta con il menù Berrino]. [Article in Italian]. Available from: http://www.ilfattoalimentare.it/milano-ristorazione-berrino-scartimense-scolastiche.html
Monasta L, Batty GD, Cattaneo A, Lutje V, Ronfani L, Van Lenthe FJ, Brug J, 2010. Early-life determinants of overweight and obesity: a review of systematic reviews. Obes Rev 11:695-708.

Saccares S, Morena V, Condoleo R, Marozzi S, Ermenegildi A, Saccares S, Scognamiglio U, 2012. [Applicazione di un modello di valutazione degli scarti nella ristorazione scolastica: opportunità per monitorare diversi fattori di rischio alimentare]. [Article in Italian]. Ital J Food Safety 1:5962. Available from: http://www.pagepressjournals.org/index.php/ijfs/article/view/ijf s.2012.3.59/458

Scognamiglio U, Salvia A, Paolucci S, Garbagnati F, Caltagirone C, Musico M, 2012. Validity of a questionnaire for the semi-quantitative evaluation of dietary intake of hospitalized persons compared with weighed records. J Hum Nutr Diet 25:526-33.

SINU, 1996. [LARN. Livelli di assunzione raccomandati di energia e nutrienti per la popolazione italiana]. [Article in Italian] Available from: http://www.sinu.it/documenti/20121016_LARN_bologna_sintesi_prefinale.pdf 